Необходимо также отметить дефицит квалифицированных кадров, способных осуществлять антикризисное управление именно АПК с учетом его специфики, а также отсутствие системы комплексных государственных мер по оказанию поддержки организациям-должникам.

\section{СПИСОК ЛИТЕРАТУРЫ}

1. Вотиева 3.А. Роль сельского хозяйства в обеспечении продовольственной безопасности России // Известия УрГЭУ. - 2011. - №5(37).- С. 177-182.

2. Данилова Н.Ф., Коновалова Т.Л., Сараева И.В. Некоторые проблемы аграрного сектора России в условиях международных санкций // Аграрный научный журнал. - 2017. - № 11. - С. 86-90.

3. Минтусов В.К. Направления совершенствования регулирования импорта продовольствия в Российской федерации: дис. ... канд. экон. наук. -М., 2016. - 157 c.

4. Минченко Л.В., Соколова Е.А. Продовольственная безопасность России, роль сельского хозяйства в ее обеспечении // Научный журнал НИУ ИТМО. Серия «Экономика и экологический менеджмент.2014. - № 4.- С. 284-301.

5. Официальный сайт Федеральной службы гос- статистики. - Режим доступа: gks.ru.

6. О несостоятельности (банкротстве): [Федер. закон: принят Гос. Думой 26 окт. 2002 г.: по состоянию на 3 июля 2016]. - Режим доступа: http://www. consultant.ru.

Данилова Наталия Федоровна, канд. экон. наук, доиент кафедры «Экономическая теория», Саратовский социально-экономический институт (филиал) РЭУ им. Г.В. Плеханова. Россия.

410003, г. Саратов, ул. Радищева, 89.

Тел.:(8452)36-28-23.

Кабанцева Наталия Гавриловна, канд. экон. наук, доцент кафедры «Финансы и кредит», Саратовский национальный исследовательский государственный университет имени Н.Г. Чернышевского. Россия.

410013, г. Саратов, ул. Астраханская , 83.

Тел.: (8452) 21-36-44.

Сараева Ирина Викторовна, канд. сочиол. наук, доиент кафедры «Финансы», Саратовский социально-экономический институт (филиал) РЭУ им. Г.В. Плеханова. Россия.

410003, г. Саратов, ул. Радищева, 89.

Тел.:(8452)36-28-23.

Ключевые слова: сельскохозяйственные предприятия; не состоятельность; банкротство; наблюдение; финансовое оздоровление; конкурсная реализация имущества и имущественных прав.

\title{
ANALYSIS OF PROBLEMS OF DEVELOPMENT OF DOMESTIC AGRICULTURE AND IMPLEMENTATION OF BANKRUPTCY PROCEDURES
}

Danilova Natalia Fedorovna, Candidate of Economic Sciences, Associate Professor of the chair "Economic Theory", Saratov Socio-economic Institute (branch) of Russian Economic University named after G.V. Plekhanov. Russia.

Kabantseva Natalia Gavrilovna, Candidate of Economic Sciences, Associate Professor of the chair "Finance and Credit”, Saratov State National Research University named after N.G. Chernyshevskiy. Russia.

Saraeva Irina Viktorovna, Candidate of Sociological Sciences, Associate Professor of the chair "Finance", Saratov Social and Economic University (branch), Russian Economic University named after G.V. Plekhanov. Russia.
Keywords: agricultural enterprises; insolvency; bankruptcy; supervision; financial rehabilitation; competitive sale of property and property rights.

In the article the problems of national agro-industrial complex development are examined, including the problem of the farmers' insolvency. The factors which are responsible for the slow pace of domestic agriculture's development are highlighted. The analysis of the bankruptcy procedure, the conclusions on the development of domestic agriculture and the peculiarities of bankruptcy proceedings against the farmers are included.

УдК 368.025.61. 332.14

\section{МЕТОДИЧЕСКИЕ ПОДХОДЫ И ОПЫТ КОЛИЧЕСТВЕННОЙ ОЦЕНКИ ФИНАНСОВЫХ РИСКОВ СЕЛЬСКОХОЗЯЙСТВЕННЫХ ПРЕДПРИЯТИЙ}

\author{
МЕЛЬНИКОВА Юлия Владимировна, Саратовский государственный аграрный университет \\ имени Н.И. Вавилова
}

ОСИПОВА Наталья Николаевна, Саратовский государственный аграрный университет имени Н.И. Вавилова

Представлены результаты анализа риска ликвидности для сельскохозяйственнъх предприятий - производителей растениеводческой продукции Новоузенского района Саратовской области. Установлена прогнозная оценка уровня финансового риска в зависимости от объемов производства и рыночных иен. Авторами выделены наиболее действенные меры по управлению финансовыми рисками для аграрного сектора экономики.

Введение. В условиях рыночных отношений проблема анализа и оценки рисков приобретает всё большее значение. Потребность в исследованиях в данной области является актуальной, поскольку проблема риска тесно связана с финансовой устойчивостью организации, позво- ляющей ей свободно маневрировать денежными средствами, обеспечивать своевременность платежей и расширение производства. Особое значение вопрос измерения рисков приобретает в агропромышленном комплексе, поскольку функционирование сельскохозяйственных пред- 
приятий заведомо сопровождается риском, выражающемся в недостижении планируемых результатов в необходимые сроки. Чтобы выжить в условиях свободного рынка, предприятиям АПК необходимо заранее, еще до осуществления инвестиций в производство, иметь отчетливое представление о реальных перспективах не только возврата денежных средств, но и получения прибыли [7].

Под финансовыми рисками обычно понимается вероятность возникновения непредвиденных финансовых потерь (снижения прибыли, доходов и т. п.) в ситуации неопределенности условий финансовой деятельности предприятия АПК. Одной из разновидностей финансового риска является риск ликвидности (или так называемый «коммерческий риск») - это риск, который может возникнуть в процессе реализации сельскохозяйственной продукции, производимой или закупаемой предприятием. Одной из основных причин риска ликвидности является снижение объемов реализации продукции вследствие изменения конъюнктуры рынка. Таким образом, при принятии управленческих решений в конкретных ситуациях руководство предприятия АПК должно учитывать корректно полученные оценки риска.

Авторами проведен анализ риска ликвидности для сельскохозяйственных предприятийпроизводителей растениеводческой продукции Новоузенского района Саратовской области. Новоузенский район территориально располагается в юго-восточной части Саратовской области. Этот район относится к одним из наиболее засушливых районов Саратовской области, климат его резко континентальный: максимальная температура наблюдается в июле на уровне $+44^{\circ} \mathrm{C}$, минимальная температура отмечается в январе-феврале на уровне $-44^{\circ} \mathrm{C}$. Среднее количество осадков за год фиксируется от 350 мм до 400 мм. Почвы в районе каштановые карбонатные и солончаковые лугово-каштанные [6].

Ведущей отраслью района является сельское хозяйство, в частности - растениеводство. Предприятия специализируются в основном на производстве зерна, овощей, картофеля. В структуре производства продукции растениеводства Новоузенского района зерновые культуры занимают $86 \%$, овощи - $10 \%$, картофель - 3 \%, подсолнечник - $1 \%$ [9].

Естественно, что функционирование предприятий-производителей растениеводческой продукции в сложных климатических условиях сопряжено с риском, что и определило интерес авторов к рассматриваемой теме и ее актуальность.

Целью исследования является анализ и количественная оценка финансовых рисков сельскохозяйственных организаций, связанных, прежде всего, с возникновением непредвиденных фи- нансовых потерь от изменения цен реализации основной продукции растениеводства.

Методика исследований. Концептуальной основой для проведения научного исследования стали фундаментальные положения, категории и принципы экономического анализа. Теоретической основой исследования являются общепринятые методы количественного анализа, а именно статистический метод оценки риска, суть которого заключается в определении вероятности возникновения потерь на основе статистических данных периода, предшествующего текущим наблюдениям. Уровень (величина, степень) риска измеряется на основе таких статистических показателей, как математическое ожидание, дисперсия, среднеквадратическое (стандартное) отклонение, коэффициент вариации и колеблемость возможного результата $[5,7]$.

Математическое ожидание случайной величины в статистике - это сумма произведений всевозможных значений случайной величины на вероятности этих значений:

$$
M[X]=\sum_{i=1}^{n} x_{i} \cdot p_{i},
$$

где $X$ - случайная величина, $x_{i}$ - возможные значения случайной величины, $p_{i}$ - вероятности значений. Другими словами, математическое ожидание есть среднеожидаемое значение при многократном повторении испытаний.

Дисперсия - это мера разброса значений случайной величины относительно ее математического ожидания. Дисперсия представляет собой степень колеблемости изучаемого статистического показателя. Чем выше колебания, тем выше колеблемость. Вычисление величины дисперсии осуществляется согласно следующей формуле:

$$
D=M\left[(X-M[X])^{2}\right]
$$

где $D$ - дисперсия; $X$ - случайная величина, определенная на некотором вероятностном пространстве, $M$ - математическое ожидание случайной величины $X$.

Одним из наиболее распространенных показателей при оценке уровня финансового риска является среднеквадратическое (стандартное) отклонение. Показатель характеризует степень рассеивания значений случайной величины относительно ее математического ожидания. Формула расчета стандартного отклонения следующая:

$$
\sigma=\sqrt{\left[(X-M[X])^{2}\right]},
$$

где $\sigma$ - среднеквадратическое (стандартное) отклонение.

Коэффициент вариации определяет степень отклонения ожидаемого значения результата от его математического ожидания. Его расчет осуществляется по формуле: 


$$
C V=\mp \frac{\sigma}{\mathrm{M}} \cdot 100 \% \text {. }
$$

Коэффициент вариации выражается в процентах и варьирует в пределах от 0 \% до $100 \%$. Чем выше его величина, тем значительнее выражена колеблемость. Коэффициент вариации $C V$ позволяет определить уровень риска. Установлена следующая шкала оценки риска для различных значений коэффициента вариации:

менее $10 \%$ - низкий уровень риска;

от $10 \%$ до $25 \%$ - средний уровень риска;

более $25 \%$ - высокий уровень риска [5, 7].

Информационной базой исследования являлись труды ученых-экономистов, нормативноправовые документы Российской Федерации, аналитические обзоры и официальные документы Минсельхоза России, базы данных Росстата и интернет-ресурсы по вопросам оценки финансовых рисков.

Результаты исследований. На основе вышеописанной методики авторы провели оценку риска возникновения непредвиденных финансовых потерь при реализации произведенной продукции от изменения уровня рыночных цен. Исходными данными послужили официальные сведения Федеральной службы государственной статистики РФ о динамике валового сбора продукции растениеводства по Новоузенскому району Саратовской области (табл. 1) и цен ее реализации (см. рисунок).

Анализируя данные табл. 1, отметим положительную динамику производства всех указанных культур, что свидетельствует о достаточно высоком уровне производства.

Анализ рисунка показывает, что в последние годы (начиная с 2013 г.) наблюдается высокий уровень нестабильности в динамике цен на растениеводческую продукцию. Поэтому для сопоставимости данных в дальнейших расчетах целесообразнее перейти к темпам роста цен. В результате вычислений согласно формулам (1)(4) получены статистические характеристики, представленные в табл. 2.

Анализ табл. 2 показывает, что наибольшей колеблемостью и, как следствие, наибольшему риску $(26,3$ \%) подвержена выборка по подсол-

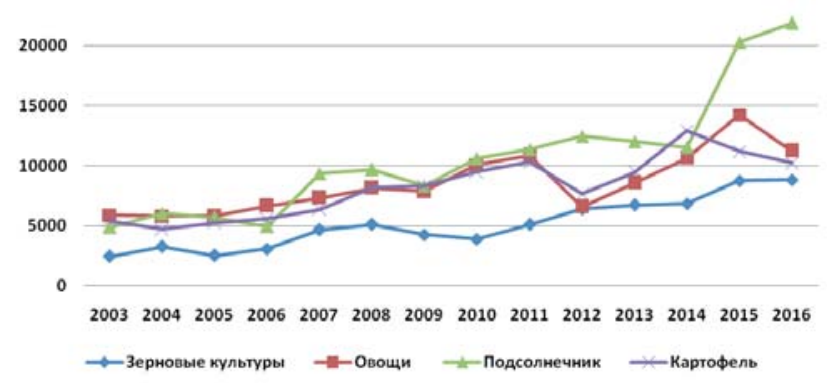

Средние иены производителей сельскохозяйственной продукиии, реализованной сельскохозяйственными организациями, по годам [9] нечнику. Расчеты подтверждают факт нестабильности рыночных цен на подсолнечник, отмеченныйдругимиавторамивсвоихисследованиях $[1,2]$. Наименьшими показателями колеблемости среди выбранных культур обладают овощи. Уровень риска изменения цены для них составляет 8,6 \%. Согласно шкале оценки риска можно сделать вывод о том, что рассчитанный уровень риска для темпов роста цен на овощи является низким, на зерновые культуры и картофель - средним, а для подсолнечника - высоким.

Как известно, уровень финансового риска, выполняющий роль одного из ведущих показателей оценки уровня финансовой безопасности любого предприятия, характеризует степень защиты его финансовой деятельности от угроз внешнего и внутреннего характера. Для оценки возможного финансового риска при производстве продукции растениеводства необходимо иметь расчетные данные о плановых показателях объема производства и прогнозных уровнях цен на соответствующие культуры. Авторами статьи рассчитаны прогнозные значения объемов производства и цен на рассматриваемые культуры на период с 2018-2020 гг. При прогнозировании использован инерционный метод, суть которого состоит в анализе имеющейся статистической выборке данных, выявлении тенденций ее вариации и экстраполяции закономерностей на прогнозный период. Уравнения полиномиальных моделей для прогнозирования соответствующих показателей представлены в табл. 3. Результат прогноза в соответствии с указанными моделями представлен в табл. 4.

На основе прогнозных данных табл. 4 рассчитаны прогнозные значения возможного уровня дохода производителей от реализации продукции растениеводства (табл. 5).

Анализируя данные табл. 4-5, можно сделать вывод о том, что производство зерновых сохранит лидирующие позиции в производственной структуре продукции растениеводства Новоузенского района Саратовской области. Значительную часть получаемой прибыли (более 83 \%) для производителей в первую очередь составит прибыль от реализации именно зерновых культур. Очевидно, что для снижения возможных потерь при планировании объемов реализации произведенной продукции и прибыли производителям необходимо учитывать риск изменения цен.

На основании всех вышеприведенных расчетов оценка уровня финансового риска при производстве продукции представлена в табл. 6.

Результаты расчетов показывают, что при производстве зерновых культур возможные потери могут составить ежегодно от 108,4 до 112,5 млн руб., подсолнечника - от 2,6 до 3 млн руб., картофеля - от 3,2 до 3,8 млн руб., овощей - от 6,6 до 7,1 млн руб. Очевидно, что для 
Динамика валового сбора, т [9]

\begin{tabular}{|l|c|c|c|c|c|c|c|c|c|c|}
\hline \multicolumn{1}{r|}{ Год } & 2007 & 2008 & 2009 & 2010 & 2011 & 2012 & 2013 & 2014 & 2015 & 2016 \\
\hline Керновые культуры & 132489,6 & 146456,5 & 34665,2 & 35362,9 & 75614,3 & 48664,1 & 69138,6 & 102936,1 & 7727,1 & 110586,4 \\
\hline Подсолнечник & 482,5 & 522,8 & 485,8 & 345,9 & 993,7 & 1257,1 & 1205,0 & 400,0 & 432,0 & 565,1 \\
\hline Картофель & 3600,0 & 1136,0 & 740,0 & 731,2 & 1642,0 & 1309,5 & 1336,0 & 1500,0 & 1203,0 & 1500,0 \\
\hline Овощи & 5207,1 & 5234,0 & 5000,3 & 4852,8 & 6579,9 & 7268,4 & 8661,5 & 9193,0 & 4113,7 & 3130,0 \\
\hline
\end{tabular}

Таблица 2

Описательная статистика выборки темпов роста цен

\begin{tabular}{|l|c|c|c|c|}
\hline \multicolumn{1}{|c|}{ Культура } & $\begin{array}{c}\text { Зерновые } \\
\text { культуры }\end{array}$ & Картофель & Подсолнечник & Овощи \\
\hline Математическое ожидание & 1,11 & 1,08 & 1,17 & 1,10 \\
\hline Стандартное отклонение & 0,2264 & 0,1714 & 0,2967 & 0,094 \\
\hline Колеблемость выборки & 0,2033 & 0,1588 & 0,2638 & 0,0857 \\
\hline Дисперсия выборки & 0,01512 & 0,02938 & 0,08806 & 0,008 \\
\hline Коэффициент вариации & $20,3 \%$ & $15,8 \%$ & $26,3 \%$ & $8,6 \%$ \\
\hline
\end{tabular}

Таблица 3

\section{Уравнения моделей прогнозирования}

\begin{tabular}{|c|c|c|}
\hline Культура & $\begin{array}{c}\text { Уравнение модели для прогнозирования объема } \\
\text { производства и коэффициент детерминации }\end{array}$ & $\begin{array}{c}\text { Уравнение модели для прогноза цен и коэффи- } \\
\text { циент детерминации }\end{array}$ \\
\hline $\begin{array}{l}\text { Зерновые } \\
\text { культуры }\end{array}$ & $\begin{array}{c}y=1480,3 x^{3}-36914 x^{2}+183264 x+1 E+06 \\
R^{2}=0,5373\end{array}$ & $\begin{array}{c}y=0,993 x^{3}-4,7829 x^{2}+225,33 x+1693,6 \\
R^{2}=0,937\end{array}$ \\
\hline Картофель & $\begin{array}{c}y=50,964 x^{3}-1184 x^{2}+3649,9 x+49374 \\
R^{2}=0,8518\end{array}$ & $\begin{array}{c}y=-3,7425 x^{3}+99,532 x^{2}-202,62 x+3998 \\
R^{2}=0,8808\end{array}$ \\
\hline Подсолнечник & $\begin{array}{c}y=40,731 x^{4}-938,9 x^{3}+7023,9 x^{2}-18384 x+18215 \\
R^{2}=0,6104\end{array}$ & $\begin{array}{c}y=10,599 x^{3}-221,17 x^{2}+1942 x+641,54 \\
R^{2}=0,9169\end{array}$ \\
\hline Овощи & $\begin{array}{c}y=-60,416 x^{3}+1215,5 x^{2}-2032,3 x+23211 \\
R^{2}=0,628\end{array}$ & $\begin{array}{c}y=2,6261 x^{3}-69,542 x^{2}+1013,5 x+2317,4 \\
R^{2}=0,8035\end{array}$ \\
\hline
\end{tabular}

\section{Результаты инерционного прогноза}

\begin{tabular}{|l|c|c|c|}
\hline \multicolumn{1}{|c|}{ Год Культура } & \multicolumn{1}{c|}{2018} & 2019 & 2020 \\
\hline \multicolumn{2}{|c|}{ Прогнозные значения обьема производства растениеводческой продукции, т } \\
\hline Зерновые культуры & 60565,5 & 58971,8 & 57378,0 \\
\hline Подсолнечник & 529,6 & 546,4 & 563,3 \\
\hline Картофель & 1640,7 & 1708,7 & 1776,6 \\
\hline Овощи & 5972,4 & 5967,1 & 5961,9 \\
\hline \multicolumn{2}{|c|}{ Прогнозные значения динамики цен на продукцию растениеводства, руб./т } \\
\hline Зерновые культуры & 8819,1 & 9242,4 & 9665,6 \\
\hline Подсолнечник & 19414,0 & 20406,3 & 21398,5 \\
\hline Картофель & 12657,8 & 13176,4 & 13695,0 \\
\hline Овощи & 12880,8 & 13393,6 & 13906,4 \\
\hline
\end{tabular}

Таблица 5

Расчет прогнозного уровня дохода от реализации продукции растениеводства, млн руб.

\begin{tabular}{|l|c|c|c|}
\hline \multicolumn{1}{|c|}{ Год } & 2018 & 2019 & 2020 \\
\hline Керльтура & & & \\
\hline Подсолые культуры & 534,14 & 545,04 & 554,59 \\
\hline Картофель & 10,28 & 11,15 & 12,05 \\
\hline Овощи & 20,77 & 22,51 & 24,33 \\
\hline
\end{tabular}

Прогнозная оценка уровня финансового риска, млн руб.

\begin{tabular}{|l|c|c|c|}
\hline \multicolumn{1}{|c|}{ Год } & 2018 & 2019 & 2020 \\
\hline Культура & & & \\
\hline Подновые культуры & 108,43 & 110,64 & 112,58 \\
\hline Картофель & 2,60 & 2,82 & 3,05 \\
\hline Овощи & 3,28 & 3,56 & 3,84 \\
\hline
\end{tabular}


снижения степени влияния финансового риска возникает необходимость заблаговременного применения верных управленческих решений.

Существуют разные методы управления финансовыми рисками для повышения эффективности сельскохозяйственного производства. Одним из распространенных методов является диверсификация. Применительно к производственной деятельности сельскохозяйственного предприятия под диверсификацией принято понимать расширение ассортиментной линейки производимой продукции, изменение ее вида. Такие мероприятия обеспечивают повышение эффективности производства, получение экономической выгоды. В настоящий момент актуальность диверсификации производства в отрасли сельского хозяйства возрастает [3].

Другим методом управления рисками является страхование, главная функция которого - обеспечение страхователей адекватным страховым покрытием в случае негативных экономических последствий, вызванных рисками. Поэтому страхование призвано обеспечить экономическую защиту, повышая экономическую стабильность предприятия в целом [4]. Страхование способствует повышению эффективности сельскохозяйственного производства и, как следствие, в определенной мере стабилизирует финансовое состояние предприятия.

Еще одной мерой поддержки производителей в условиях риска является государственное субсидирование. Федеральным и региональным бюджетом предусмотрены средства для осуществления субсидирования различных программ и мероприятий по развитию сельского хозяйства, направленных на поддержание производителей сельскохозяйственной продукции в трудных экономических условиях. Все это в совокупности призвано обеспечить рост экономической эффективности на основе управления рисками [8].

Заключение. Проведенное исследование показывает важную роль анализа рисков в ходе управления финансовой деятельностью сельскохозяйственного предприятия. Проведенное авторами исследование показывает необходимость и целесообразность учета величины финансового риска при принятии рациональных управленческих решений. Поэтому оценка риска и использо- вание актуальных методов управления рисками должны стать основой финансового менеджмента предприятия АПК, что позволит снизить уровень потенциальных потерь предприятия в ходе реализации произведенной продукции, повысив тем самым эффективность хозяйственной деятельности.

\section{СПИСОК ЛИТЕРАТУРЫ}

1. Александрова Л.А., Мельникова Ю.В. Проблемы прогнозирования рыночной конъюнктуры в системе стратегического планирования производства и реализации подсолнечника // Аграрный научный журнал. - 2017. - № 12. - С. 79-82.

2. Александрова Л.А., Мельникова Ю.В. Ценообразующие факторы на рынке подсолнечника // Аграрный научный журнал. - 2016. - № 7. - С. 71-79.

3. Аронов А.М., Петров А.Н. Диверсификация производства: теория и стратегия развития. - СПБ: Лениздат, 2000. - 126 с.

4. Афанасъева И.И. Особенности ценообразования на рынке зерновых // Экономика и предпринимательство. - 2013. - № 6(35) - С. 128-131.

5. Елисеева И.И., Юзбашев М.М. Общая теория статистики: учебник. М.: Финансы и статистика, 2005. - 657 c.

6. Новоузенский район Саратовской области. Режим доступа: http://www. ruzgd.ru/novouzensk raion.shtml.

7. Прибыткова Г.В. Анализ и оценка рисков предприятий производственной сферы в процессе инвестиционного проектирования // Вестник МГТУ. 2005. - T. 8. - № 2. - С. 300-305.

8. Санду И.С. Эффективность сельскохозяйственного производства / под ред. И.С. Санду [и др.]. - М.: ФГБНУ «Росинформагротех», 2013. - 228 с.

9. Федеральная служба государственной статистики. - Режим доступа: http://www.gks.ru/.

Мельникова Юлия Владимировна, канд. экон. наук, старший преподаватель кафедры «Экономическая кибернетика», Саратовский государственный аграрный университет имени Н.И. Вавилова. Россия.

Осипова Наталья Николаевна, ведущий специиалист отдела подготовки научно-педагогических кадров, Саратовский государственный аграрный университет имени Н.И. Вавилова. Россия.

410012, г. Саратов, Театральная пл., 1.

Тел.: 89172070408; e-mail:n.n.osipova@mail.ru.

Ключевые слова: финансовый риск; ликвидность; уровень риска; иена реализации; прибыль; прогноз; эффективность; диверсификация; страхование.

\section{METHODICAL APPROACHES AND EXPERIENCE OF QUANTITATIVE ASSESSMENT OF FINANCIAL RISKS OF AGRICULTURAL ENTERPRISES}

Melnikova Yuliya Vladimirovna, Candidate of Economic Sciences, Senior Teacher of the chair "Economic Cybernetics”, Saratov State Agrarian University named after N.I. Vavilov. Russia.

Osipova Natalia Nikolaevna, Leading Specialist of the Department of training of scientific and pedagogical staff, Saratov State Vavilov Agrarian University in honor of N.I. Vavilov. Russia.

Keywords: financial risk; liquidity; level of risk; the selling price; profit; forecast; efficiencv; diversification; insurance.
The results of liquidity risk analysis for agricultural enterprises - producers of crop production in Novouzensk district of the Saratov region are presented. The forecasted estimation of the level of financial risk is determined depending on the volumes of production and market prices. The authors identified the most effective measures to manage financial risks for the agricultural sector of the economy. 